Nevșehir Bilim ve Teknoloji Dergisi Cilt 6(2) 556-562 2017

DOI: 10.17100/nevbiltek.354821

URL: http://dx.doi.org/10.17100/nevbiltek.354821

\title{
Farklı Oranlarda Si İçeren TRIP Çeliğinin Mig-Mag Kaynak Tekniği İle Kaynağı ve Mikroyapısının İncelenmesi
}

\author{
Cemal ÇARBOĞA*, Bülent KURT, Serkan DAL \\ Nevşehir Hacı Bektaş Veli Üniversitesi,Mühendislik Mimarlık Fakütesi,Metalurji ve Malzeme
}

Mühendisliği Bölümü, Nevşehir

$\ddot{O z z}$

Bu çalışmada, tipik TRIP (Transformation Induced Plasticity) çeliğinin mevcut silisyum miktarı değiştirilerek vakumsuz indüksiyon ocağında farklı Si içeriğine sahip TRIP çeliği üretimi gerçekleştirilmiştir. Tipik TRIP çeliği \% ağırlıkça 0,2 C, 1,7 Mn, 1,5 Si içermektedir. Üretimi gerçekleştirilen TRIP çeliğinin Si oranı ise 0,6 - 1,15 - 1,7 oranlarında değiştirilmiştir. Döküm ve haddeleme işlem sonrasında, MIGG-MAG kaynak tekniği kullanılarak birleştirilmiştir. Böylece, farklı oranda Si içeren TRIP çeliğinin kaynak edilebilirliği araştırılmıştır. Bu amaçla, kaynak bölgesinin mikroyapısı incelenmiş ve kaynak bölgesi kesitinden mikrosertlik analizleri alınarak sertlik profili çıkarılmıștır.

Anahtar Kelimeler: TRIP Çeliği, Kaynak, Mikroyapı

\section{The Welding of TRIP Steel with Different Si Contents by Mig-Mag Welding Technique and Its Microstructure Investigation}

\begin{abstract}
In this study, TRIP (Transformation Induced Plasticity) steel production with different Si content carried out by adding Si in TRIP steel with using non-vacuum induction furnace. Typical TRIP steel contains $0.2 \mathrm{wt} \% \mathrm{C}, 1.7 \mathrm{Mn} 1.5 \mathrm{Si}$. Al content of the steel was changed to $0,6-1,15-1,7$ ratios. After then, the rolled specimens were joined by robotic Gas-Metal Arc Welding (GMAW) technique. Hence, the weldability of the different Si content into the TRIP was investigated. For this purpose, the microstructures of the weld region were investigated and hardness profile achieved by being done micro-hardness analysis of the samples taken from the weld cross section.
\end{abstract}

Keywords: TRIP Steel, Welding, Microstructure.

\footnotetext{
"e-mail: ccarboga@nevsehir.edu.tr
} 


\section{Giriş}

Yüksek dayanımlı çelikler (HSS (high strength steel)) üzerine özellikle otomotiv uygulamaları için 1970'li yıllardan beri oldukça yoğun olarak çalışmalar yapılmaktadır. Günümüzde geliştirilen yüksek dayanımlı ve şekillendirilebilir çelikler otomobil, parça ağırlığının azaltılması ve çarpışmanın söndürülmesi özelliği ile yolcu güvenliği açısından son derece önemli bir fonksiyona sahiptirler. TRIP (Transformation Induced Plasticity) çelikleri; yüksek mukavemet ve yüksek süneklik açısından en iyi kombinasyonunu sergilediğinden HSS içerisinde çok önemli yer tuttuğu söylenebilir [1-7].

TRIP çeliklerinin plastik davranışları; Çift-fazlı ve TRIP-özellikli çeliklerde, martensit oluşumu ile ilişkilendirilen, ferrit martensit arayüzeyine yakın ferrit bölgelerindeki serbest dislokasyonlar ve gerilim alanları vardır [3, 9]. Geleneksel TRIP çeliklerinde(kütle yüzdesi, \%: C 0,2, Mn 1.5 ve Si 1 5) düşük kaynak edilebilirlik ve sıcak galvanizleme performansı literatürde başlıca problemler olarak belirtilmektedir. Ayrıca yüksek Si içeriğinin çeliğin özelliklerini kötüleştirdiği ve çeliğin C içeriğininse azaltılmasının faydalı olacağı yönünde öneriler vadır[1]. Genel olarak, Mn östenit oluşumunu teşvik eder ve böylece bir ostenit stabilizörü olarak kalıcı ostenitin hacim fraksiyonunu arttırır[9]. Tamamen ostenitik yapıya sahip olan TRIP çeliklerinin düşük akma mukavemeti olumsuz özelliklerdendir. Bu özelliği iyileştirmek için tane küçültme, nano ikizler oluşturulması ve çökelti sertleşmesi gibi yöntemler kullanılmaktadır[10]. TRIP çeliklerinin mikroyapıları karmaşıktır ve mikro yapısının incelenmesi için optik mikroskopi (OM), taramalı elektron mikroskopisi (SEM), transmisyon elektron mikroskobu (TEM) ve elektron geri saçılım kırınımı (EBSD) teknikler kullanılabilir. TRIP çeliklerinin ana uygulama alanı otomotiv endüstrisidir. Bu nedenle, iyi mekanik özellikler yanında iyi bir kaynak edilebilirlikte beklenir. Literatürde kaynak edilebilirlik yanında, kaynaklı bölgelerin mikroyapı ve özellikleri üzerine yeterince çalışma bulunmamaktadır[11].

Yapılan bu çalışmanın amacı, \% 0,62-1,15-1,70 oranlarında Si içeriğine sahip TRIP çeliklerinin MIG MAG kaynak yöntemi ile kaynak edilebilirliği ve kaynak sonrasında elde edilen yapıların makro ve mikro yapılarının incelenmesidir. Bu amaçla kaynak bölgesinden alınan kesitin 1şık mikroskobu ile mikroyapısı incelenerek sonrasında mikrosertlik profilleri elde edilmiştir. Elde edilen ITAB ve kaynak metalini içeren veriler incelenerek yorumlanmıştır.

\section{Materyal ve Metot}

Çalışmada kullanılan farklı oranlarda silisyum içeriğine sahip TRIP çeliğikleri, döküm işlemi sonrası haddeleme ile $5 \mathrm{~mm}$ kalınlığa sahip lama halindedir. Kaynak için haddelenmiş malzemelerden 115x65x5 mm'lik boyutlarda numuneler kesilerek hazırlanmış ve Tablo 2'de gösterilen koşullarda Magmaweld RS 350 MK marka kaynak makinası kullanılarak MİG MAG kaynak tekniği ile tek pasoda birleştirilmiştir. Kullanılan TRIP çeliği numunelerin kimyasal bileşimleri Tablo 1'de gösterildiği gibidir.

Tablo 1. Deneyde kullanılan numunelerin kimyasal bileșimleri.

\begin{tabular}{lccccccc}
\multicolumn{8}{c}{$\begin{array}{c}\% \\
\text { Bileşim }\end{array}$} \\
\hline No & C & Mn & Si $\begin{array}{c}\mathbf{B} \\
\text { (ppm) }\end{array}$ & Al & Ti & Fe \\
\hline 11 & 0,14 & 1,62 & $\mathbf{0 , 6 2}$ & 0,0007 & 0,078 & 0,0025 & 97,28 \\
12 & 0,13 & 1,60 & $\mathbf{1 , 1 5}$ & 0,0008 & 0,076 & 0,0035 & 96,8 \\
13 & 0,13 & 1,59 & $\mathbf{1 , 7 0}$ & 0,0009 & 0,62 & 0,0032 & 96,2 \\
\hline
\end{tabular}


Döküm işlemi sonrası haddeleme ile $5 \mathrm{~mm}$ kalınlığında lama haline getirilen malzemeler 115x65x5 mm'lik boyutlarda kesilerek hazırlanmış ve Tablo 2'deki şartlarda tek pasoda kaynak edilmiştir.

\begin{tabular}{|c|c|c|c|c|}
\hline $\begin{array}{c}\text { Akım şiddeti } \\
\text { (A) }\end{array}$ & Kullanılan Gaz & Marka-Yöntem & $\begin{array}{c}\text { Tel Çıkma Hızı } \\
\text { mm/saniye }\end{array}$ & Paso Sayısı \\
\hline 110 & Karbondioksit & $\begin{array}{c}\text { Magmaweld-Mig } \\
\text { Mag }\end{array}$ & 8 & 1 \\
\hline
\end{tabular}

Kaynağı yapılan TRIP çeliği örnekleri sonrasında oda koşullarında kendi halinde açık havada soğutulmuştur. Sonrasında birleştirilen TRIP çeliği numuneleriden, kaynak bölgesinin metalografik olarak incelenmesi amacıyla, kaynak bölgesi ve 1sıdan etkilenen bölgeyi(ITAB) kapsayan örnekler Metcon Metacut 250 marka hassas kesme cihazıyla kesilerek elde edilmiştir. Zımpara işleminden geçirilen kaynaklı kesit yüzeyler 1 m'luk elmas süspansiyon ile hassas olarak parlatıldı ve \% 3'lük Nital çözeltisi ile 6 sn süre ile daldırma yöntemi kullanılarak dağlama işlemleri gerçekleştirildi. Dağlanarak elde edilen mikroyapılar Clemex marka optik mikroskop kullanılarak incelendi. TRIP çeliği örneklerinin kaynak metali ve ana malzeme arasındaki sertlik yapısını ve farklarını incelemek amacıyla kaynak metali, ITAB ve ana malzemeyi de kapsayan mikrosertlik ölçümleri gerçekleştirilerek mikrosertlik profilleri elde edildi.

\section{Bulgular}

Kaynak yapılan TRIP çeliği örneklerine ait kaynak dikişi fotoğrafı Şekil 1'de görülmektedir. Kaynak dikişlerinde son derece iyi bir nüfuziyet meydana geldiği ve kaynak dikişi görünümünde gayet düzenli, homojen bir kaynak yapısının oluştuğu görülmektedir. Optik mikroskop ile incelenen örneklerde yaklaşık 5 mm’lik bir ITAB bölgesinin bulunduğu görülmüştür.

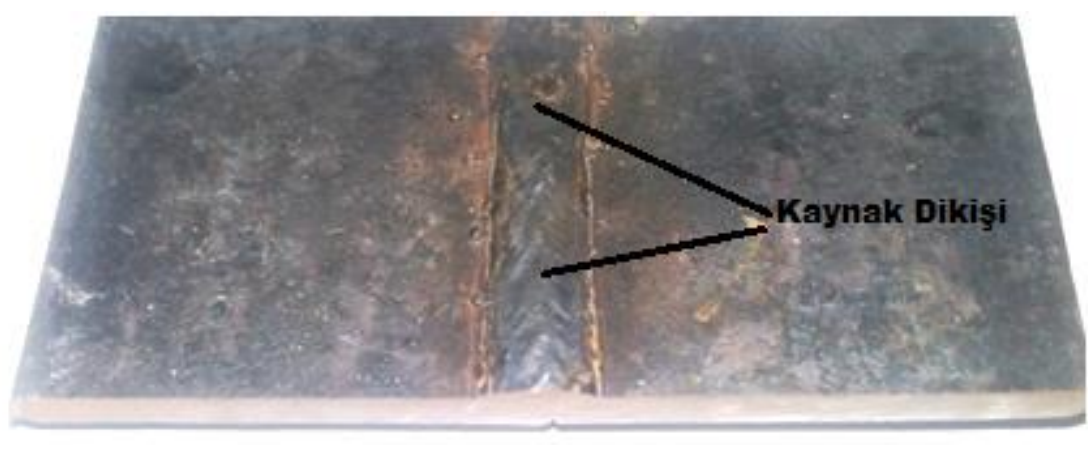

Şekil 1. Kaynak dikişi ve kesitinin makro görünümü.

Şekil 2'de sırasıyla \% 0,62-1,15-1,70 oranlarında Si ilave edilmiş numunenin mikroyapıları görülmektedir. Literatürde TRIP çeliklerinin tipik bir mikroyapısının ağırlıklı olarak ferrit, bunun yanında beynit ve kalıntı östenit içerebileceği belirtilmektedir[13]. Bu çalışmada Si oranlarına bağlı olarak optik mikroyapı numunelerinden her üç numunede de ferrit+perlit+beynitik yapının oluştuğu görülmektedir. Artan silisyum içeriği ile birlikte çok önemli bir mikroyapı değişimi olmadığı da açıkça görülmektedir. 


\section{Nevşehir Bilim ve Teknoloji Dergisi Cilt 6(2) 556-562 2017}
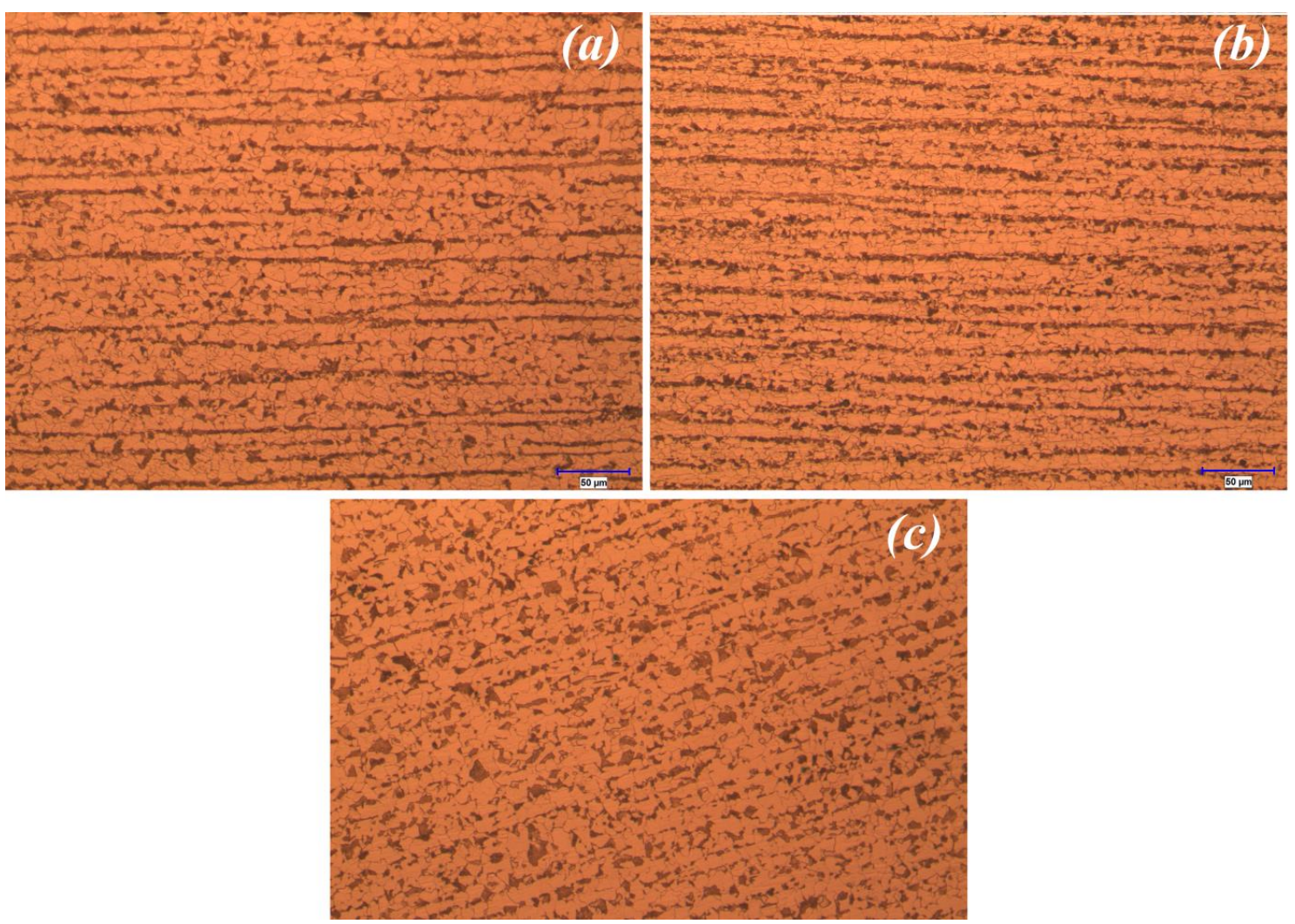

Şekil 2. 0,62-1,15-1,70 oranlarında Si ilave edilmiş numunelerin Optik Mikroyapı Fotoğrafları [a) $\% 0,62 \mathrm{Si}$, b) $\% 1,15 \mathrm{Si}$, c) $\% 1,70 \mathrm{Si}]$
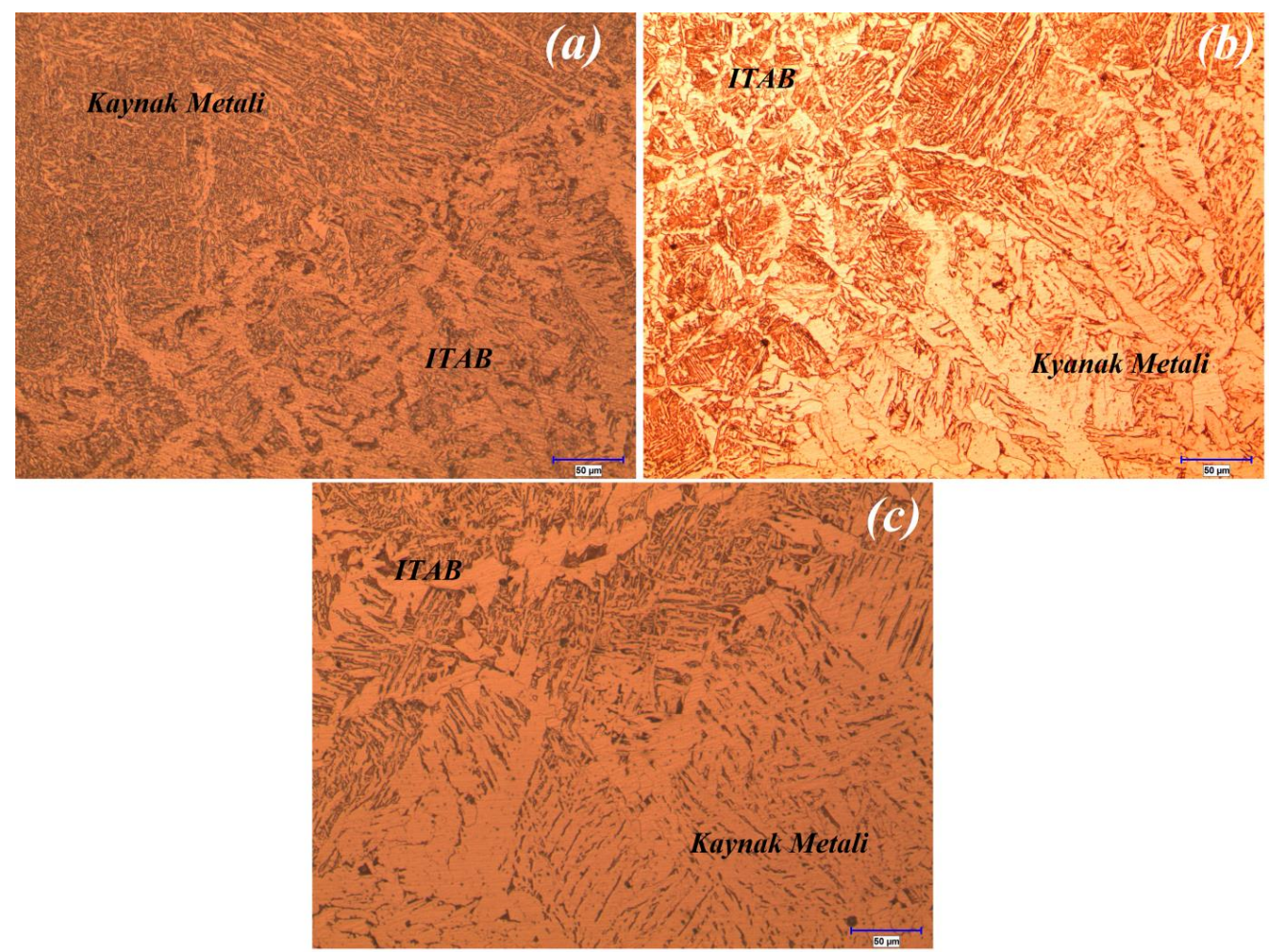

Şekil 3. Kaynak Metali-ITAB Ara Bölgesinin Optik Mikroyapı Fotoğrafları [a) $\% 0,62 \mathrm{Si}$, b) $\% 1,15 \mathrm{Si}$, c) $\% 1,70 \mathrm{Si}$. 
\% 0,62-1,15-1,70 oranlarında Si ilave edilmiş numunelerin kaynak metali ve ITAB ara bölgeden alınan optik mikroyapı fotoğrafları Şekil 3'te görülmektedir. Yapmış olduğumuz çalışmada kaynak edilen numuneler oda sıcaklığında kendi haline soğumaya bırakılmıştır. Tüm nümunelerde geçiş, kaynak metalinden ITAB'a doğru kısmen delta ferrit iğneleri ile birlikte beynitik oluşumla gerçekleşmiştir. Bu durumun, sınır bölgesinde kaynak metali iç kısımlarına kıyasla nispeten daha yüksek soğuma hızından dolayı meydana geldiği düşünülmektedir. Wang ve arkadaşları[14] ise, yapmış oldukları çalışmada kimyasal bileşimi 0.19C-1.45Mn-0.70Si-0.89Al-0.11Ti-0.08V(ağırlıkça\%) olan TRIP çeliğine üç farklı 1sıl işlem uygulayarak poligonal ferritik matrisi, beynitik matris, ferrit ve martenzitik matrisli yapılar elde etmişlerdir. Bu yapıların elde edilmesinde malzemelerin maruz kaldıkları ısı ve soğuma hızının etkilerini ortaya koymuşlardır.

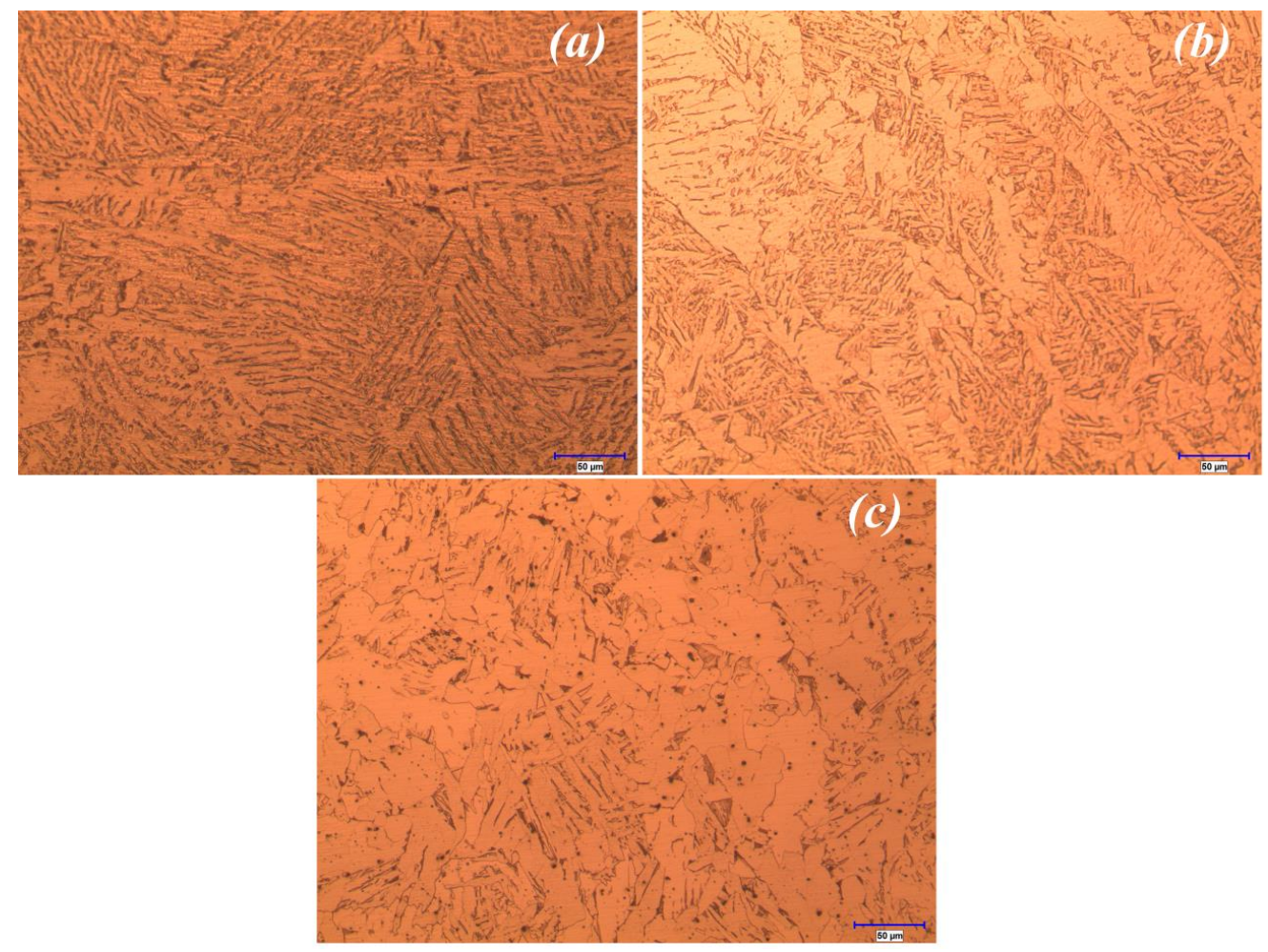

Şekil 4. Kaynak Metali Optik Mikroyapı Fotoğrafları [a) \%0,62 Si, b) \%1,15 Si, c) \%1,70 Si]

Farklı oranlarda Si içeren TRIP çeliği numunelerin bir çizgi halinde kaynak metali, ITAB ve ana malzemeden alınan mikrosertlik profilleri Şekil 5' de görülmektedir. Silisyumun oranlarının TRIP çeliklerinde artışı ile mikrosertlik değerlerinin arttığı yapılan çalışmalarda görülmektedir[12]. Benzer bir şekilde yapılan bu çalışmada da Si oranlarının \%0,62 'den \%1,70’e yükselmesi kaynakta kullanılan ana malzemenin mikrosertliğini arttırmıştır. Her üç numunede de ITAB bölgesi sertliğini yüksek olduğu buna karşın kaynak metali sertliğinin düştüğü grafikte açık bir şekilde görülmektedir. Kaynak metalindeki sertlik düşüşünün ferrit ağırlıklı bir mikroyapıya sahip olmasından kaynaklandığı düşünülmektedir.ITAB bölgesinde ise yüksek soğuma hızı ile birlikte ferrit + beynitik yapı oluşumuyla birlikte sertlik değeri de artmıştır. 


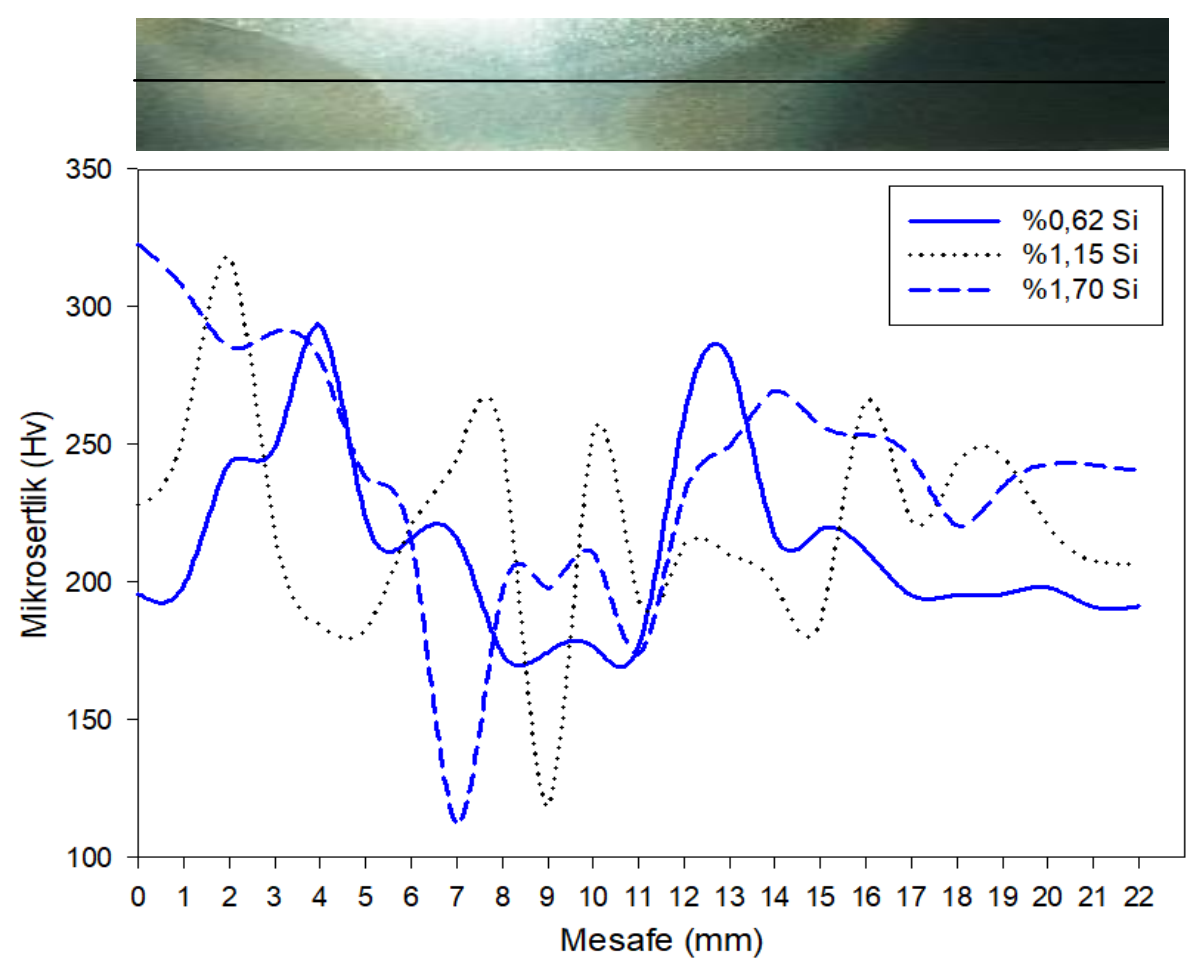

Şekil 5. \%0,62, \%1,15 ve \%1,70 oranlarda Si içeren TRIP çeliği numunelerin kaynak Metali, ITAB ve Ana Malzeme Mikrosertlik Profili.

\section{Tartışma ve Sonuç}

Farklı oranlarda Si içeren TRIP çeliği robotik MIG-MAG kaynak tekniği kullanılarak birleştirilmiş ve Si elementinin TRIP çeliğinin kaynak edilebilirliği üzerindeki etkileri araştırılmıştır. Kaynak metali ve ITAB üzerine yoğunlaşılan çalışmada şu sonuçlara ulaşılmıştır.

- Tüm numunelerde çok iyi nüfuziyetli ve mikro çatlak oluşumunun gözlenmediği kaynak dikişileri elde edilmiştir.

- Tüm numunelerde ITAB gölgesi genellikle ferrit tanesi ve beynit yapısından meydana gelmiştir

- Si oranının kaynak bölgesi mikrosertlik profili üzerine çok önemli bir etkisi olmamıştır.Ancak ana malzemede Si oranlarının artışı literatürle uyumlu olarak mikrosertliği artmıştır.

\section{Kaynaklar}

[1] Li L., De Cooman B.C., Iju R., Vleugels J., Zhang M., Shı W., "Design of TRIP Steel With High Welding and Galvanizing Performance in Light of Thermodynamics and Kinetics", Journal Of Iron And Steel Research, International, 14(6), 37-41, 2007.

[2] Taş, Z., 'Nb-V alaşımlı borlu çeliklerinde mikroyapı - mekanik özelliklerin ilişkisi', Erciyes Üniversitesi Fen Bilimleri Enstitüsü Dergisi, Kayseri, 22,152-160, 2006.

[3] Meyer L, Straburger C., Schneider C., "Effect and present application of the microalloying elements $\mathrm{Nb}, \mathrm{V}, \mathrm{Ti}, \mathrm{Zr}$, and B in HSLA steels", HSLA Steels, Metallurgy and Applications: Proceedings of an International Conference on HSLA Steels '85, 4-8 November, 29-45s, Beijing, China, 1985. 
[4] Cohen, M., Hansen S. S.," On the fundamentals of HSLA steels", HSLA Steels, Metallurgy and Applications: Proceedings of an International Conference on HSLA Steels '85, 4-8 November, 61-73s, Beijing, China, 1985.

[5] Koyama R., Tsukamoto T., “Boron-added steel”, Simitomo Metals, 48, 195-197, 1996.

[6] Masakatsu U., "Hardenability of low-carbon steel and boron", Research Review on Boron in Steels and Targets for Next Century, Tokyo, 78-86, 1999.

[7] Tomoya F., "Hardenability improvement effect of the boron in TMCP", Research Review on Boron in Steels and Targets for Next Century, Tokyo, 68-72, 1999.

[8] Fountain, R. W., Chipman J., "Solubility and precipitation of boron nitride in iron-boron alloys", Transactions of the metallurgical society of AIME, 224, 599-605, 1962.

[9] Sugimotoa K., Taninoa H., Kobayashi J., "Warm ductility of $0.2 \%$ C-1.5\% Si-5\% Mn TRIPaided steel”, Materials Science \& Engineering A, 688, 237-243, 2017.

[10] Xie P., Han M., Wu C.L., Yin Y.Q., Zhu K., Shen R.H., Chen J.H., "A high-performance TRIP steel enhanced by ultrafine grains and hardening precipitates”, Materials \& Design 127, 1-7, 2017.

[11] Mujica L., Weber S., Pinto H., Thomy C., Vollertsen F., "Microstructure and mechanical properties of laser-welded joints of TWIP and TRIP steels", Materials Science and Engineering A, 527, 2071-2078, 2010.

[12] Nayaka S.S., Baltazar Hernandeza V.H., Okitaa Y., Zhou Y., "Microstructure-hardness relationship in the fusion zone of TRIP steel welds", Materials Science and Engineering A 551, 73-81, 2012.

[13] Kučerová L., Bystrianský M., "Comparison of thermo-mechanical treatment of C-Mn-Si-Nb and C-Mn-Si-Al-Nb TRIP steels”, Procedia Engineering 207, 1856-1861, 2017.

[14] Wang C., Ding H., Cai M, Rolfe B., "Characterization of microstructures and tensile properties of TRIP-aided steels with different matrix microstructure", Materials Science\&Engineering A 610, 65-75, 2014. 